\title{
Severe Hyponatremia Associated with Use of Black Cohosh during Prolonged Labor and Unsuccessful Home Birth
}

\author{
Matthew J. Blitz, MD, MBA ${ }^{1} \quad$ Michelle Smith-Levitin, MD $^{1} \quad$ Burton Rochelson, MD ${ }^{1}$ \\ ${ }^{1}$ Division of Maternal-Fetal Medicine, Department of Obstetrics and \\ Gynecology, Hofstra North Shore-LIJ School of Medicine, Manhasset, \\ New York \\ Address for correspondence Matthew J. Blitz, MD, MBA, Division of \\ Maternal-Fetal Medicine, Hofstra North Shore-LIJ School of Medicine, \\ North Shore University Hospital, 300 Community Drive, Manhasset, NY \\ 11030 (e-mail: mblitz@nshs.edu).
}

Am J Perinatol Rep 2016;6:e121-e124.

\begin{abstract}
Introduction There has been an increase in the use of herbal supplements during pregnancy, which are frequently of unproven efficacy and safety. We present a case of severe hyponatremia and altered mental status associated with the use of black cohosh during prolonged labor.

Case A 39-year-old primigravida at $38^{5 / 7}$ weeks of gestational age presented to the emergency department after she became disoriented and lethargic while laboring at home with a midwife. She had consumed several doses of black cohosh to induce and augment labor. On presentation, she was nonverbal and unable to follow commands. Her serum sodium was $114 \mathrm{mmol} / \mathrm{L}$ (range, $132-145 \mathrm{mmol} / \mathrm{L}$ ), serum osmolality was $253 \mathrm{mOsm} / \mathrm{kg}$ (range, 275-300 mOsm/kg), urine osmolality was $190 \mathrm{mOsm} / \mathrm{kg}$ (range, $300-900 \mathrm{mOsm} / \mathrm{kg}$ ), and urine sodium was $<10 \mathrm{mmol} / \mathrm{L}$. The patient soon became uncooperative and combative and a cesarean section was performed. Postoperatively, she was transferred to the intensive care unit for monitoring and correction of her

Keywords

- black cohosh

- Cimicifuga racemosa

- hyponatremia

- prolonged labor sodium. Her mental status returned to baseline and she was subsequently discharged home without further complication.

Discussion Clinically significant hyponatremia associated with pregnancy is rare. Further investigation is needed to evaluate the safety and efficacy of black cohosh and other commonly used herbal supplements during pregnancy and labor.
\end{abstract}

Amid a persistently high cesarean delivery rate in the United States, there is a growing public interest in natural childbirth, which seeks to minimize medical and surgical intervention. Although such care can be offered in a hospitalbased setting, some pregnant women are electing to have midwife-supervised, planned home births. Concomitant with this trend has been an increase in the use of complementary and alternative medicines during pregnancy, in particular herbal supplements, which are frequently of unproven efficacy and safety. We present a case of severe hyponatremia and altered mental status associated with the use of black cohosh (Actaea racemosa, Cimicifuga racemosa) during prolonged labor and unsuccessful home birth. This appears to be the first reported case of this phenomenon.

\section{Case Report}

A 39-year-old primigravida at $38^{5 / 7}$ weeks of gestational age was brought to the emergency department by ambulance after laboring at home for over 48 hours, attended by a midwife. The patient had ruptured her membranes 36 hours before and was fully dilated for 10 hours prior to presentation. During this time, she had consumed several doses of black cohosh with the intent to induce and augment labor. The patient was strongly received

August 10, 2016

accepted after revision

December 16, 2015
DOI http://dx.doi.org/

10.1055/s-0036-1579537. ISSN 2157-6998.
Copyright $\odot 2016$ by Thieme Medical Publishers, Inc., 333 Seventh Avenue, New York, NY 10001, USA. Tel: +1(212) 584-4662.
License terms

(요 (1) $\Theta$ 
committed to a natural birth experience with minimal medical intervention. She was followed by midwives for the majority of her prenatal care, initially with a university hospital-based group before transferring care at 33 weeks to a solo-midwife who specialized in home birth and water birth. The patient had declined genetic counseling, aneuploidy screening, and routine fetal heart rate auscultation by Doppler at her prenatal visits after expressing concern about the emission of radiation. Her prenatal course was complicated by an elevated 1-hour glucose challenge test of $156 \mathrm{mg} / \mathrm{dL}$, but she declined a 3-hour confirmatory glucose tolerance test, instead opting for finger-stick monitoring which was reportedly normal. She had a past medical history of $\beta$-thalassemia minor and had no prior surgery. She took prenatal vitamins during the pregnancy and was prescribed ferrous gluconate $325 \mathrm{mg}$ daily at 27 weeks for anemia (hemoglobin, $9.2 \mathrm{~g} / \mathrm{dL}$; range, 11.5-15.5 g/dL). No herbal medication use was documented in her outpatient medical records.

Upon arrival to the hospital, she was awake but disoriented, lethargic, nonverbal, and unable to follow commands. Per her family members, there was no seizure activity, no headache, no nausea or vomiting, no diarrhea, and no fevers. She was afebrile and normotensive with a heart rate of 95 beats per minute and a respiratory rate of 20 breaths per minute. Pupils were equal, round, and reactive to light. She was responsive to painful stimuli but not to verbal or tactile stimuli. Neurologic function could not be fully assessed due to her altered mental status. Abdominal exam noted a gravid, nontender uterus. Respiratory effort appeared normal and lungs were clear to auscultation bilaterally. Mild bilateral lower extremity edema was noted. A limited vaginal exam determined that the fetal head was high and that delivery was not imminent. Her physical exam was otherwise unremarkable. Abdominal ultrasound demonstrated a fetal heart rate of 150 beats per minute and visible fetal movement. Laboratory evaluation was significant for a serum sodium of $114 \mathrm{mmol} / \mathrm{L}$ (range, 132-145 mmol/L), serum osmolality of $253 \mathrm{mOsm} / \mathrm{kg}$ (range, 275-300 mOsm/kg), urine osmolality of $190 \mathrm{mOsm} /$ $\mathrm{kg}$ (range, 300-900 mOsm/kg), and urinary sodium of $<10$ $\mathrm{mmol} / \mathrm{L}$. Her white blood cell count was $23.1 \mathrm{~K} / \mu \mathrm{L}$ (range, 3.8$10.5 \mathrm{~K} / \mu \mathrm{L})$ and her finger-stick glucose was $113 \mathrm{mg} / \mathrm{dL}$. thyroid stimulating hormone (TSH), cortisol, and urine protein were within normal limits. Noncontrast computed tomography of the head found no evidence of infarction, hemorrhage, or mass. The decision was made to transfer the patient to labor and delivery.

After transfer to the labor floor, the fetal heart rate was initially category 1 . Hypertonic saline ( $3 \%$ sodium chloride) was administered intravenously at $30 \mathrm{~mL} /$ hour. After less than an hour, the patient became uncooperative and combative and the decision was made to proceed with cesarean delivery prior to any further normalization of serum sodium. A male infant weighing 3,270 g was delivered with Apgar scores of 3 and 9 at 1 and 5 minutes, respectively. The newborn was noted to have thick meconium below the vocal cords. Postoperatively, the patient's serum sodium was $117 \mathrm{mmol} / \mathrm{L}$ and she was transferred to the intensive care unit (ICU) for further management. In the ICU, her sodium was closely monitored and gradually corrected. The hypertonic saline was restarted and continued for approximately 3 hours. Her mental status slowly returned to baseline. After her serum sodium increased to $134 \mathrm{mmol} / \mathrm{L}$, she was transferred to a postpartum floor and was subsequently discharged home without further complications.

\section{Discussion}

Approximately 6 to $9 \%$ of pregnant women in the United States report the use of herbal treatments during pregnancy, most commonly echinacea, "pregnancy tea," and ginger. ${ }^{1,2}$ Black cohosh, a homeopathic remedy traditionally used by Native Americans for a variety of gynecologic ailments, including menopausal symptoms and dysmenorrhea, is recommended by some midwives as an alternative to prostaglandins and oxytocin for inducing and augmenting labor. ${ }^{3}$ It is sometimes combined with other herbs such as squaw vine (Mitchella ripens), raspberry (Rubus idaeus), blue cohosh (Caulophyllum thalictroides), and false unicorn (Chamaelirium luteum) in a preparation known as "mother's cordial," which is thought to facilitate delivery by improving uterine tone. Although many advise caution during pregnancy due to limited data, ${ }^{4}$ one survey of certified nurse-midwives suggests that approximately half of them use herbal preparations to stimulate labor, and among them, $45 \%$ use black cohosh. ${ }^{5}$

Normal pregnancy is associated with physiologic changes in water and sodium homeostasis. An increase in intravascular volume and resetting of the osmostat result in a decrease in serum sodium of approximately 3 to $5 \mathrm{mmol} / \mathrm{L}$ and a decrease in plasma osmolality of approximately 5 to $10 \mathrm{mOsm} / \mathrm{kg}$. Under normal physiologic conditions, the serum sodium concentration and the plasma osmolality are maintained in a very narrow range despite variations in water intake. Antidiuretic hormone, also known as arginine vasopressin, is a neurohypophysial hormone that regulates water reabsorption; when present, it allows urinary concentration, and when absent, it allows urinary dilution.

Although clinically significant hyponatremia in pregnancy is uncommon, it is also likely underrecognized, particularly in labor. ${ }^{6}$ Hyponatremia is typically defined as a serum sodium of less than 134 to $136 \mathrm{mmol} / \mathrm{L}$ in the nonpregnant patient. There is even less consensus on the definition of severe hyponatremia, sometimes referred to as profound hyponatremia, which is commonly defined as a serum sodium of less than 115 to $125 \mathrm{mmol} / \mathrm{L}^{7}$ Severe acute hyponatremia, in which the sodium concentration drops rapidly $(<36-$ 48 hours), is a medical emergency that may result in maternal complications such as cerebral edema, seizures, coma, brain stem herniation, respiratory arrest, and death. ${ }^{8,9}$ Hyponatremic encephalopathy may manifest as headache, nausea, vomiting, and altered mental status. Signs of impending herniation include seizures, neurogenic pulmonary edema, hypercapnic respiratory failure, obtundation, hyperemesis, dilated pupils, and decorticate or decerebrate posturing.

Management of hyponatremia during pregnancy can be challenging, especially during labor and delivery, as there are no definitive guidelines. In contrast to severe chronic 
hyponatremia which may be treated by fluid restriction, severe acute hyponatremia should be managed more aggressively using hypertonic saline until a mild hyponatremic level is reached. ${ }^{10}$ Commonly used preparations of hypertonic saline include 3,5 , and $7 \%$ sodium chloride. Overly rapid correction of hyponatremia risks the development of central pontine myelinolysis in which the myelin sheath of nerve cells in the brainstem is damaged. The goal of emergency therapy is to increase the serum sodium by 4 to $6 \mathrm{mmol} / \mathrm{L}$ over several hours. An intravenous $100 \mathrm{~mL}$ bolus of $3 \% \mathrm{NaCl}$ may be given over 10 to 15 minutes. Alternatively, an infusion may be administered, preferably in a monitored setting. Regardless of the regimen selected, the correction should not exceed 8 to 10 $\mathrm{mmol} / \mathrm{L}$ in 24 hours. Serum sodium should therefore be measured every 2 hours to ensure an optimal rate of correction and allow adjustments as necessary. Urine output should be monitored closely. Excessive infusions of oxytocin should be avoided. Fetal complications of maternal hyponatremia are poorly described in the literature and often inextricably linked to the etiology of the maternal pathology; they may include fetal hyponatremia, diuresis, polyhydramnios, respiratory distress, hyperbilirubinemia, and neonatal seizures. $^{11-14}$

The patient in the earlier case had a severe acute hypovolemic, hypoosmolar, hyponatremia. A serum osmolality $<280 \mathrm{mOsm} / \mathrm{kg}$ excludes pseudohyponatremia (isotonic hyponatremia) and the presence of osmotically active solutes (hypertonic hyponatremia). A urine osmolality $>100 \mathrm{mOsm} /$ $\mathrm{kg}$ suggests impaired water excretion and excludes primary polydipsia and reset osmostat syndrome. A urine sodium $<10 \mathrm{mmol} / \mathrm{L}$ indicates a hypovolemic state of extrarenal origin such as from skin losses (excessive sweating or burns) and gastrointestinal losses (vomiting or diarrhea), and decreases the likelihood of syndrome of inappropriate antidiuretic hormone secretion or renal salt wasting which are typically associated with urine sodium $>40 \mathrm{mmol} / \mathrm{L}$. Thyroid and adrenal function, both of which are required for free water excretion, were normal. No evidence suggests that there were significant gastrointestinal losses. There was no documentation of excessive oral fluid intake prior to admission. Prolonged obstructed labor, which is much more common in developing countries, is often associated with hypernatremia secondary to dehydration. ${ }^{15}$ Exercise-induced hyponatremia associated with endurance athletic activities, which may bear some resemblance to prolonged obstructed labor in the developed world, is thought to be caused by a combination of moderate sodium loss through sweat and excessive ingestion of hypotonic fluids. Although the exact etiology in this case remains unclear, in the absence of any other known contributing factors, it appears that black cohosh may have played an integral role in this pathology.

The active constituent(s) and mechanism(s) of action of black cohosh are poorly understood. Adverse effects are usually mild and reversible, and include gastrointestinal upset, rashes, headaches, dizziness, and mastalgia. ${ }^{16}$ However, hepatotoxicity resulting from black cohosh has been reported. ${ }^{17}$ Some studies have demonstrated an estrogenic or estrogen receptor-binding effect while others have not.
Düker et al found that black cohosh suppresses endogenous luteinizing hormone secretion but has no effect on folliclestimulating hormone levels. ${ }^{18}$ Nadaoka et al found that it affects both the hypothalamic-pituitary-adrenal axis and the sympathetic adrenomedullary system under stress conditions in a murine model, specifically acting to alleviate acute stress responses. ${ }^{19}$ Woo et al concluded that black cohosh inhibited catecholamine secretion by blocking sodium influx through nicotinic acetylcholine receptors in the adrenal medulla. ${ }^{20}$ Other studies have suggested that it acts as an analgesic. In the aforementioned case, a clear causality relationship cannot be definitively established between black cohosh and severe hyponatremia, but common alternative etiologies were excluded.

In conclusion, clinically significant hyponatremia associated with pregnancy is rare. Although the etiologic mechanism in this case is uncertain and possibly multifactorial, the use of black cohosh may have contributed to this pathologic process. The exact dosage and preparation used by the patient in this case is unknown. Formulations vary by manufacturer and lot number. The active components and the potency of black cohosh and other herbal products are frequently uncertain. Furthermore, patients often do not inform their health care providers about the use of these products and there is significant potential for drug-herb interactions. Given the paucity of literature on black cohosh and other herbal supplements commonly used during pregnancy and labor, further investigation is warranted to evaluate their safety and efficacy.

\section{Acknowledgment}

We thank Stephanie Augustine for her assistance in acquiring and reviewing medical records.

\section{References}

1 Louik C, Gardiner P, Kelley K, Mitchell AA. Use of herbal treatments in pregnancy. Am J Obstet Gynecol 2010;202(5):439. e1-439.e10

2 Ernst E. Herbal medicinal products during pregnancy: are they safe? BJOG 2002;109(3):227-235

3 Kistin SJ, Newman AD. Induction of labor with homeopathy: a case report. J Midwifery Womens Health 2007;52(3):303-307

4 Dugoua JJ, Seely D, Perri D, Koren G, Mills E. Safety and efficacy of black cohosh (Cimicifuga racemosa) during pregnancy and lactation. Can J Clin Pharmacol 2006;13(3):e257-e261

5 McFarlin BL, Gibson MH, O'Rear J, Harman P. A national survey of herbal preparation use by nurse-midwives for labor stimulation. Review of the literature and recommendations for practice. J Nurse Midwifery 1999;44(3):205-216

6 Moen V, Brudin L, Rundgren M, Irestedt L. Hyponatremia complicating labour-rare or unrecognised? A prospective observational study. BJOG 2009;116(4):552-561

7 Spasovski G, Vanholder R, Allolio B, et al; Hyponatraemia Guideline Development Group. Clinical practice guideline on diagnosis and treatment of hyponatraemia. Eur J Endocrinol 2014;170(3): G1-G47

8 Adrogué HJ, Madias NE. Hyponatremia. N Engl J Med 2000; 342(21):1581-1589 
9 Adrogué HJ. Consequences of inadequate management of hyponatremia. Am J Nephrol 2005;25(3):240-249

10 Gross P, Reimann D, Neidel J, et al. The treatment of severe hyponatremia. Kidney Int Suppl 1998;64:S6-S11

11 Roberts TJ, Nijland MJ, Williams L, Ross MG. Fetal diuretic responses to maternal hyponatremia: contribution of placental sodium gradient. J Appl Physiol (1985) 1999;87(4): 1440-1447

12 Chapman $\mathrm{TH}$, Hamilton M. Water intoxication presenting as maternal and neonatal seizures: a case report. J Med Case Reports 2008;2:366

13 Singhi SC, Chookang E. Maternal fluid overload during labour; transplacental hyponatraemia and risk of transient neonatal tachypnoea in term infants. Arch Dis Child 1984;59(12): 1155-1158

14 Singhi S, Chookang E, Hall JS. Intrapartum infusion of aqueous glucose solution, transplacental hyponatraemia and risk of neonatal jaundice. Br J Obstet Gynaecol 1984;91(10):1014-1018

15 Ekanem EI, Umoiyoho A, Inyang-Otu A. Study of electrolyte changes in patients with prolonged labour in Ikot Ekpene, a rural community in Niger delta region of Nigeria. ISRN Obstet Gynecol 2012;2012:430265

16 Borrelli F, Ernst E. Black cohosh (Cimicifuga racemosa): a systematic review of adverse events. Am J Obstet Gynecol 2008;199(5):455-466

17 Enbom ET, Le MD, Oesterich L, Rutgers J, French SW. Mechanism of hepatotoxicity due to black cohosh (Cimicifuga racemosa): histological, immunohistochemical and electron microscopy analysis of two liver biopsies with clinical correlation. Exp Mol Pathol 2014; 96(3):279-283

18 Düker EM, Kopanski L, Jarry H, Wuttke W. Effects of extracts from Cimicifuga racemosa on gonadotropin release in menopausal women and ovariectomized rats. Planta Med 1991;57(5):420-424

19 Nadaoka I, Yasue M, Sami M, Kitagawa Y. Oral administration of Cimicifuga racemosa extract affects immobilization stressinduced changes in murine cerebral monoamine metabolism. Biomed Res 2012;33(2):133-137

20 Woo KC, Park YS, Jun DJ, et al. Phytoestrogen cimicifugosidemediated inhibition of catecholamine secretion by blocking nicotinic acetylcholine receptor in bovine adrenal chromaffin cells. J Pharmacol Exp Ther 2004;309(2):641-649 